\title{
Discrete Propagation in Numerically Simulated Nocturnal Squall Lines
}

\author{
Robert G. Fovell, Gretchen L. Mullendore, and Seung-Hee Kim \\ Department of Atmospheric and Oceanic Sciences, University of California, Los Angeles, Los Angeles, California
}

(Manuscript received 23 May 2005, in final form 22 February 2006)

\begin{abstract}
Simulations of a typical midlatitude squall line were used to investigate a mechanism for discrete propagation, defined as convective initiation ahead of an existing squall line leading to a faster propagation speed for the storm complex. Radar imagery often shows new cells appearing in advance of squall lines, suggesting a causal relationship and prompting the search for an "action-at-a-distance" mechanism to explain the phenomenon. In the simulations presented, the identified mechanism involves gravity waves of both low and high frequency generated in response to the latent heating, which subsequently propagate out ahead of the storm. The net result of the low-frequency response, combined with surface fluxes and radiative processes, was a cooler and more moist lower troposphere, establishing a shallow cloud deck extending ahead of the storm. High-frequency gravity waves, excited in response to fluctuations in convective activity in the main storm, were subsequently ducted by the storm's own upper-tropospheric forward anvil outflow. These waves helped positively buoyant cumulus clouds to occasionally form in the deck. A fraction of these clouds persisted long enough to merge with the main line, invigorating the parent storm. Discrete propagation occurred when clouds developed into deep convection prior to merger, weakening the parent storm. The ducting conditions, as diagnosed with the Scorer parameter, are shown to be sensitive to vertical wind shear and radiation, but not to the microphysical parameterization or simulation geometry.
\end{abstract}

\section{Introduction}

For common storms, such as squall lines, propagation is dependent on the precipitation. More precisely, some of the precipitation evaporates before reaching the surface, establishing a subcloud cold pool that spreads along the ground. This pool helps lift moist, low-level air into the storm at its leading edge or gust front. Even though this ascent tends to get temporally punctuated into individual convective cells, this mechanism can be termed continuous propagation, the continuity provided by the spreading cold pool's persistence.

Yet, radar imagery often reveals new storms firing up in advance of established convection, particularly near nocturnal squall lines. The new cells often appear close enough to the established storm to suggest a causal linkage between old convection and new, but also sufficiently far ahead of the gust front that a mechanism other than cold pool lifting must be operating. In Fig. 1, for example, the new echoes appeared roughly $20 \mathrm{~km}$

Corresponding author address: Robert G. Fovell, Department of Atmospheric and Oceanic Sciences, University of California, Los Angeles, 405 Hilgard Ave., Los Angeles, CA 90095-1565.

E-mail: rfovell@ucla.edu ahead of the well-defined gust front. This phenomenon will be termed forward convective initiation, as the new developments form in the environment that the storm is propagating into (i.e., its forward environment).

Many of these new cells subsequently merge with the main convective line where, as in the case shown in Fig. 1 , their rate of development often accelerates as they overrun the gust front. If the cells develop more fully prior to merger, they may produce their own cold pools out ahead of the preexisting squall line, and perhaps remain independent storms. Following this occurrence, the original storm may weaken, possibly leaving the new convection as the only storm in the vicinity. But even if this does not occur, the episodic appearance of these new clouds implies the convection is spreading forward more quickly than the cold pool. In either case, a fundamentally discrete mode of propagation is being accomplished (Zipser 1977; Houze 1977; Crook and Moncrieff 1988; Carbone et al. 1990; Grady and Verlinde 1997; Houze 2004; among others).

In this paper, we examine a numerical simulation of organized convection in which several instances of forward convective initiation (CI) leading to discrete propagation occur during the morning hours. Figure 2 is a Hovmöller diagram from this simulation, showing 

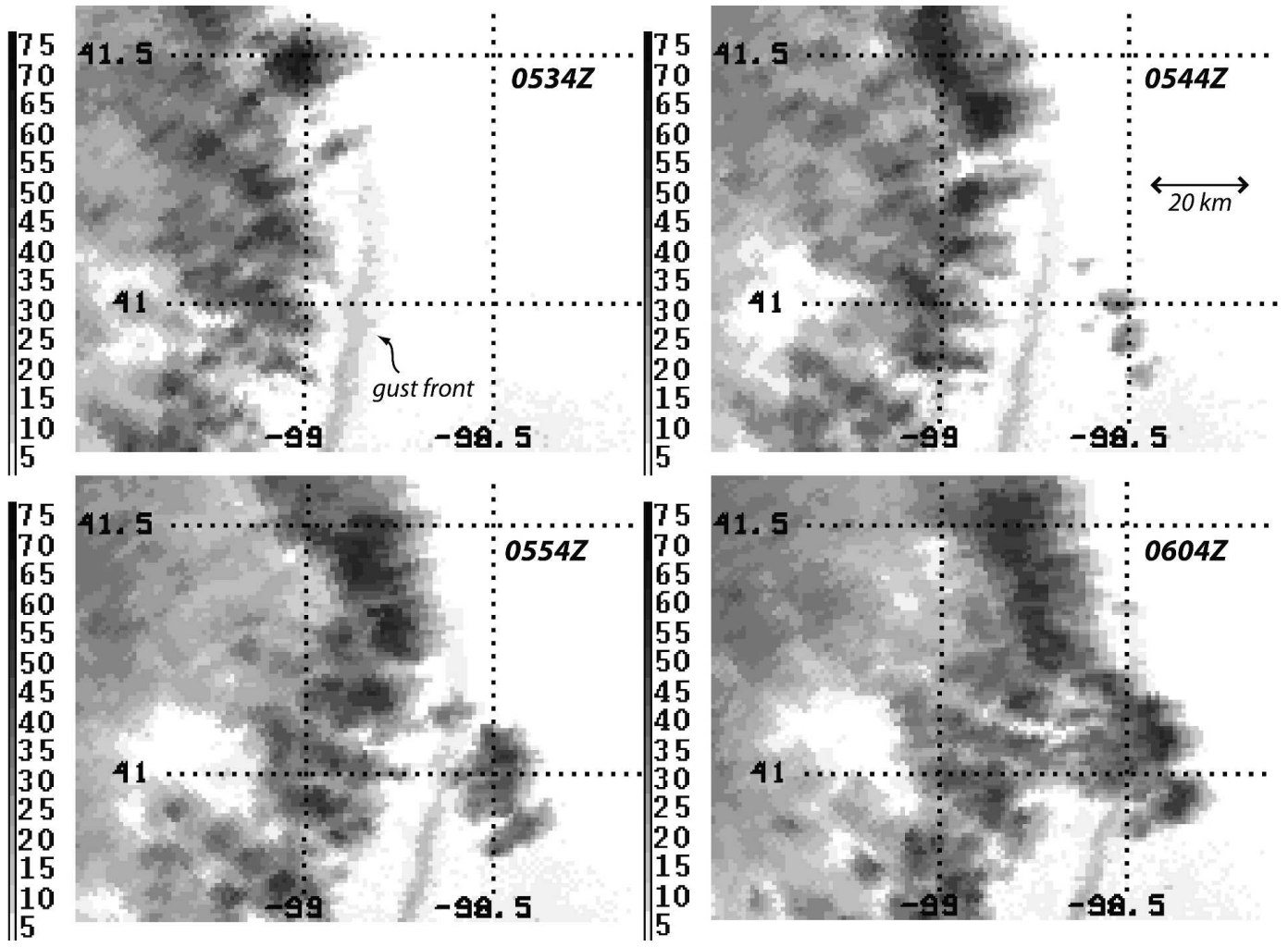

FIG. 1. Hastings, NE, Next-Generation Weather Radar (NEXRAD) imagery from 8 Jul 2003, showing radar reflectivity with superposed latitude and longitude markers.

instantaneous surface rainfall intensity over a period of $6 \mathrm{~h}$. The thick solid line traces the gust front, or leading edge of the evaporationally produced subcloud cold pool. The reference frame is translating eastward at $14.5 \mathrm{~m} \mathrm{~s}^{-1}$, and for the first few hours shown the storm was progressing about $1.2 \mathrm{~m} \mathrm{~s}^{-1}$ faster than the frame. The simulation will be more fully introduced in section 2.

Several times during the integration, discontinuous jumps in the gust front position, associated with the development of precipitating convection in the forward environment of the established line, occurred. On radar, these developments would take the appearance of new cells separated from the squall line by an echo-free gap, as in Fig. 1. The gap would progressively narrow owing to the difference in translation velocities between the new and original convection. The original storm moved eastward at approximately the speed of its cold pool, that typically being faster than the lower-tomidtropospheric winds carrying the forward clouds associated with the new convection, at least before the new convection develops an appreciably deep pool.

If a causal relationship between the old and new convection exists, then forward CI requires an "action-ata-distance" mechanism. We will describe a possible mechanism that involves gravity waves (GWs), of both low and high frequency. Regarding the former, Fovell's (2002, hererafter F02) simulations showed that a squall line can exert a substantial influence on its forward environment, for the reasons discussed by Bretherton and Smolarkiewicz (1989), Mapes (1993), and others. The influence is spread by low-frequency, nearly hydrostatic GWs excited by persistent heating and cooling occurring in and around the storm's main convective region. The first and least subtle of these waves carries the deep-tropospheric subsidence provoked by the onset of latent heat release. This subsidence propagates quickly, warming the bulk of the troposphere and enhancing the lower-tropospheric flow toward the storm. The environmental alterations can persist until the convection ceases.

This initial signal, however, is routinely found to be followed by slower moving low-frequency GWs associated with shallower vertical modes of convective heating and cooling. Although there is a broad spectrum of these waves (Mapes 1993; F02's Fig. 12), we will refer to them collectively as the " $n=2$ " mode, following Nicholls et al. (1991). This subsequent $n=2$ response is characterized by lower-tropospheric ascent. F02 showed this ascent actually overcomes the original sub- 


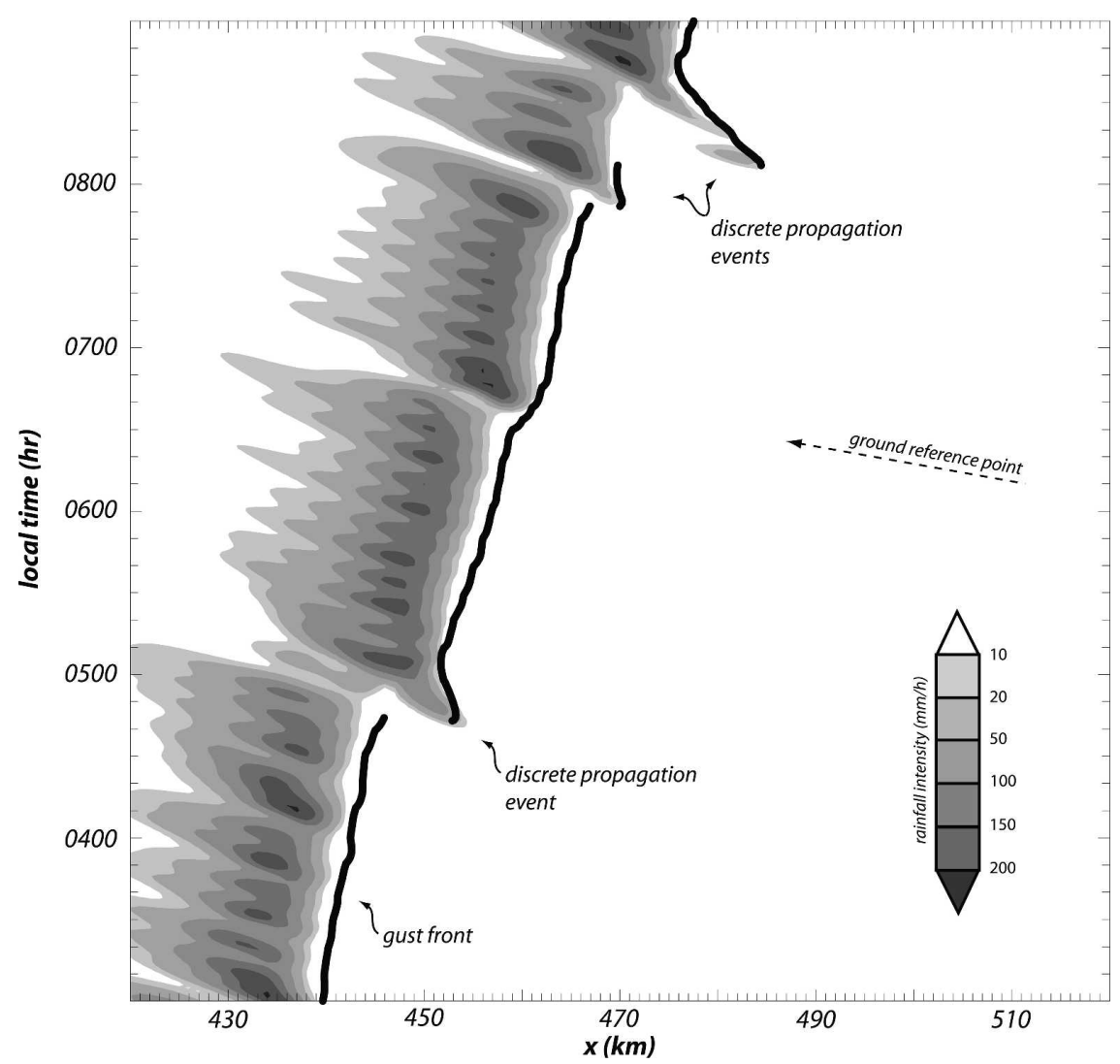

FIG. 2. Hovmöller diagram of instantaneous surface rainfall intensity between 0300 and 0900 LT from the 2D nocturnal squall-line simulation, for a portion of the simulation domain. The reference frame is that of the model, which translated eastward at $14.5 \mathrm{~m} \mathrm{~s}^{-1}$; dashed arrow follows a fixed point in space. The surface gust front location is superposed.

sidence wave's warming to establish a "cool and moist tongue" of air, typically located between 2 and $4 \mathrm{~km}$ above ground level (AGL) and extending ahead of the storm for some kilometers. The visual signature of this tongue may be a shallow deck of stratus clouds in the forward environment, if the humidity there is sufficiently high. By simultaneously increasing the relative humidity and reducing the static stability of the lower troposphere, the air in this tongue is made more favorable for convection and thus may potentially support the initiation of new cells ahead of the established storm.

In F02's simulations, however, new forward CI did not form for want of a "spark." In the present case, the spark came in the form of transient, high-frequency GWs that were continually generated in response to temporally varying heating in the main convective region. These waves were trapped by the storm's own upper- tropospheric forward anvil outflow, the "overturning updraft" (e.g., Thorpe et al. 1982) that extends out in advance of the storm. The possibility of CI was further enhanced by nocturnal cooling of the boundary layer, which brought the lower troposphere closer to saturation. Small cumulus clouds started forming sporadically within the cloud deck in the forward environment, in air forced to ascend in GW updrafts. Though many of these new clouds were short lived, a fraction survived to be carried toward the main storm, reinvigorating the established convection upon merging with it. These clouds may play a role in keeping the storm viable even as the environmental CAPE is eroded (in this case by radiative cooling).

Furthermore, a still smaller number of these clouds were able to develop into deep convection prior to the merger, generating their own cold pools. Particularly because this process typically leads to a rapid weakening of the parent storms, these new storms accomplish a fundamentally discrete propagation, increasing the storm system's effective translation speed. That is to say, the convection progresses in the direction of storm motion faster than it could by continuous propagation alone.

This paper is organized as follows: section 2 describes the numerical model and initialization, section 3 presents and analyzes a control run and briefly discusses 

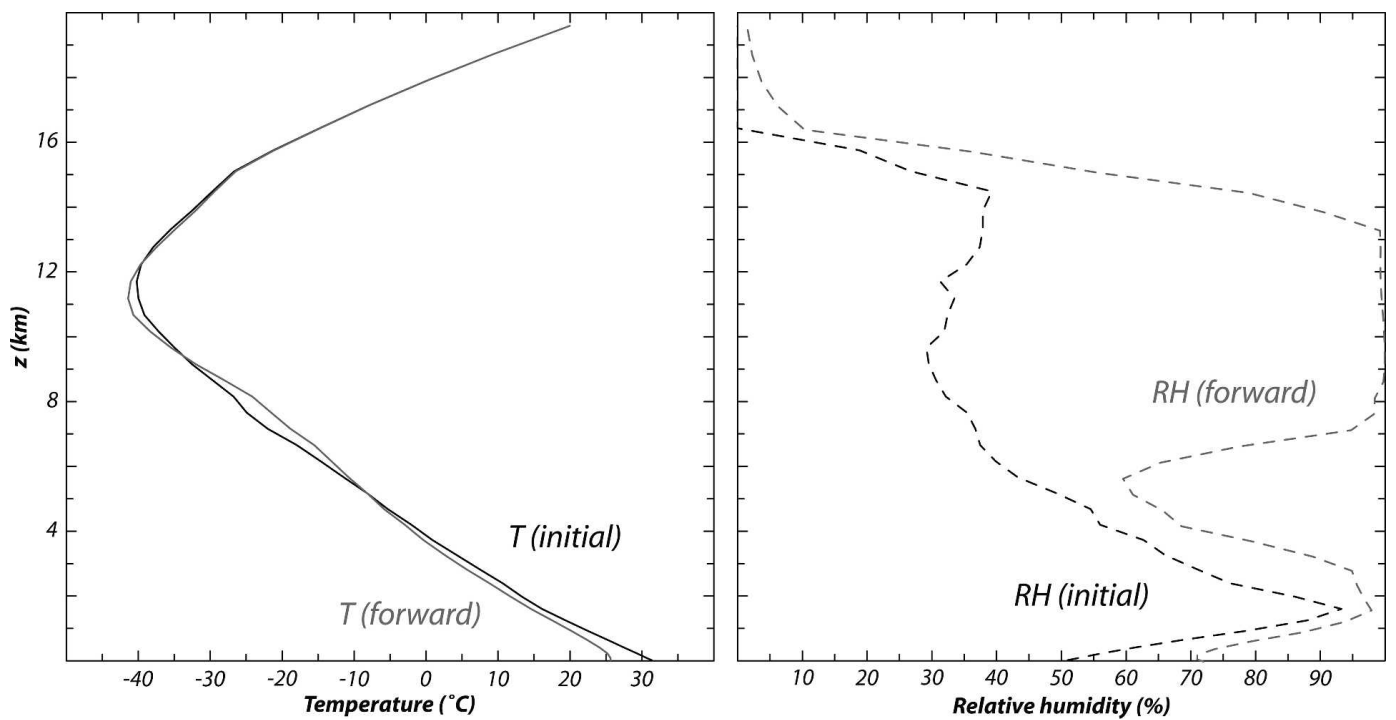

FIG. 3. Vertical profiles of temperature $\left({ }^{\circ} \mathrm{C}\right)$ and relative humidity (\%) for the base state ("initial") environment, following Fovell and Ogura (1988). Also shown are mature phase profiles forward of the storm (taken at $x=485$ km in Fig. 4).

results from sensitivity tests, and section 4 provides further discussion and the summary.

\section{Model and initialization}

Our simulations were made using the Advanced Regional Prediction System (ARPS) model (Xue et al. 2000), a compressible cloud-resolving model with parameterized microphysics. The model employed Fovell and Ogura's (1988) temperature and moisture sounding (see Fig. 3) along with a horizontal wind profile having linear, unidirectional speed shear of $3 \times 10^{-3} \mathrm{~s}^{-1}$ over the lowest $5 \mathrm{~km}$ and zero shear farther aloft. This specific case was considered in both Fovell and Dailey (1995) and Fovell and Tan (1998). Initially, this environment had a CAPE of $2500 \mathrm{~J} \mathrm{~kg}^{-1}$ and a bulk Richardson number of 106, a value commonly associated with multicellular convection (Weisman and Klemp 1982). The ground-relative surface wind was calm but the domain was translated $14.5 \mathrm{~m} \mathrm{~s}^{-1}$ eastward to keep the storm near the domain center. Thus, the uppertropospheric winds in the undisturbed environment were roughly zero in the domain-relative reference frame.

Two- and three-dimensional simulations were made. The $2 \mathrm{D}$ domain was $800 \mathrm{~km}$ wide with $1-\mathrm{km}$ horizontal grid spacing and open lateral boundaries. The $3 \mathrm{D}$ runs used a 2-km grid spacing in a $300 \mathrm{~km} \times 20 \mathrm{~km}$ domain with periodicity enforced in the shorter (alongline) direction. Both geometries employed a 21.5-km-deep domain, topped by a wave-permeable boundary, with a vertically stretched grid of 45 levels placing the highest resolution near the surface. Convection was initiated with a $2-\mathrm{K}$ warm, moist bubble. In the $3 \mathrm{D}$ runs, a line thermal was used, with $\pm 5 \%$ random perturbations superposed to encourage fully three-dimensional circulations. Because of the high degree of congruence between the $2 \mathrm{D}$ and $3 \mathrm{D}$ results, the principal emphasis is on analyzing the former.

The control simulation described herein incorporated realistic surface and atmospheric radiative processes, with surface fluxes computed using predicted surface temperature and humidity and specified exchange coefficients, and "warm rain" microphysics excluding the ice phase. Subgrid-scale mixing was represented with the model's 1.5-order turbulent kinetic energy parameterization; additionally, some background diffusion was applied to prevent nonlinear instability. The model was started at 1800 local time (LT) and integrated past sunrise. A shallow radiation inversion developed near the surface after sunset, which was at 2037 LT for this late May case. Simulations were also made excluding surface and/or atmospheric radiative forcings and including ice microphysics. Results from these sensitivity tests will be reported in the next section.

\section{Results}

\section{a. Time-averaged mature phase structure}

In the $2 \mathrm{D}$ control simulation, the model storm acquired mature characteristics, including a welldeveloped cold pool and general upshear tilt, by about 
(a) potential temperature perturbation
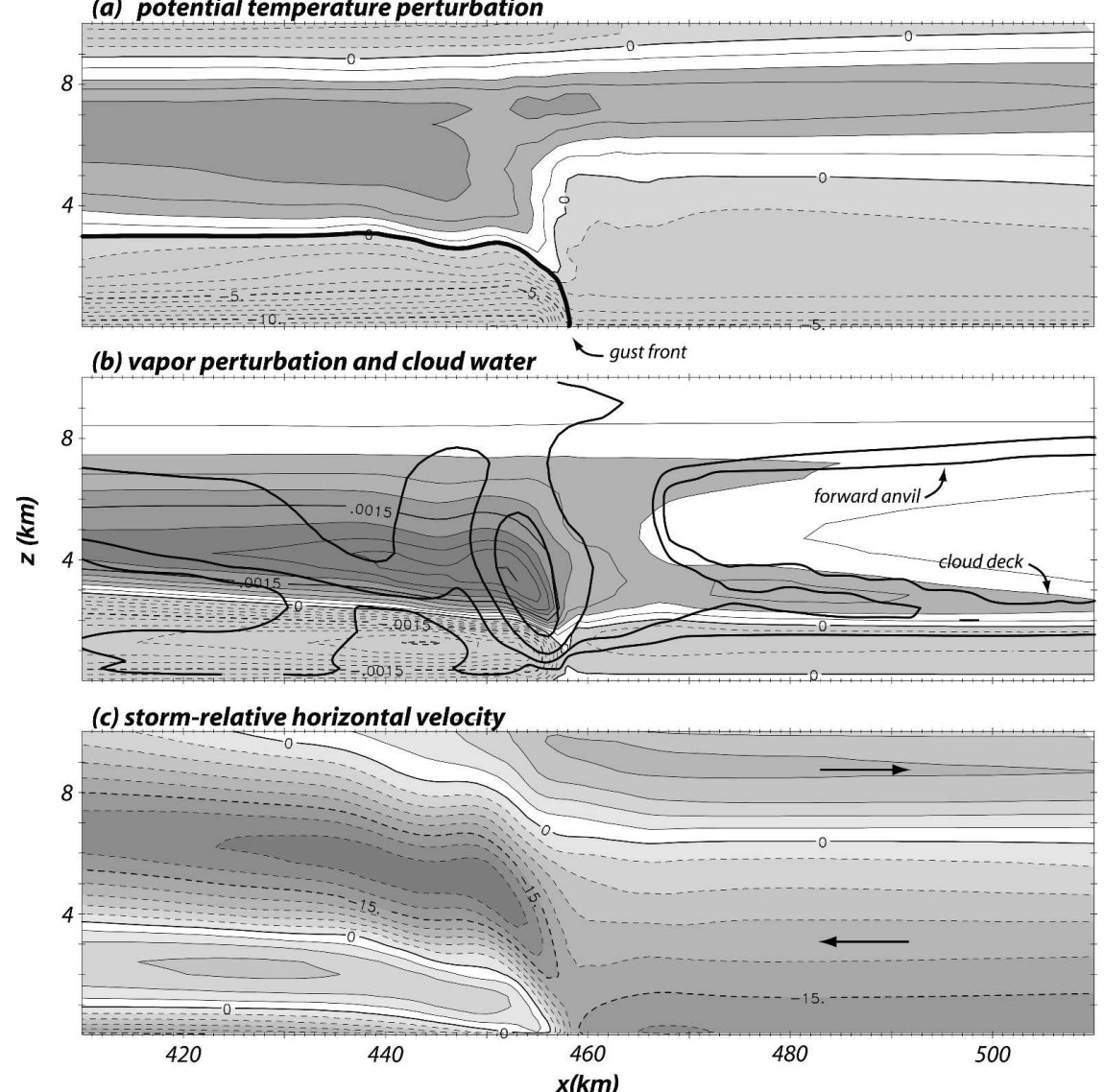

FIG. 4. Mature phase time-averaged fields for the 2D control run, with averaging performed in a storm-relative reference frame. Shaded fields are (a) potential temperature perturbation (with $1-\mathrm{K}$ contours), (b) water vapor mixing ratio perturbation $\left(0.3 \mathrm{~g} \mathrm{~kg}^{-1}\right.$ contours), and (c) storm-relative horizontal velocity ( $3 \mathrm{~m} \mathrm{~s}^{-1}$ contours). Approximate thermodynamic cold pool boundary is shown in (a). In (b), the transformed cloud water field $a q_{c}^{b}$ is superposed, with $a=1 \times 10^{4}$ and $b=0.2$, adopted to emphasize small condensate values in the cloud deck. The contour interval is 0.4 , and thus actual cloud water mixing ratios shown include $0.001,0.033$, and $0.25 \mathrm{~g} \mathrm{~kg}^{-1}$, etc. Perturbations are relative to the initial horizontally homogeneous basestate environment.

1930 LT, 90 min after the simulation commenced. For reference purposes, Fig. 4 presents perturbation fields of potential temperature $\theta^{\prime}$ and water vapor mixing ratio $q_{v}^{\prime}$, along with storm-relative horizontal velocity $u_{\text {rel }}$, made via averaging in a strictly storm-relative manner between 0400 and 0600 LT. Perturbation fields were created by subtracting the initial base-state environment. It will be seen that plenty of convective and wave activity occurred ahead (east) of the storm during the averaging interval. The more mesoscale impacts of that activity are represented in the fields shown but the individual convective elements have been smoothed out.

The averaged potential temperature field (Fig. 4a) displays the typical and expected temperature rise in the squall line's convective and trailing regions ( $x \leq 460$ $\mathrm{km}$ ) with negative perturbations both above and below.
Forward of the gust front, there was general warming above the 5-km level, with cooling beneath. The former is a combination of convective region warming exported in the storm's forward anvil outflow $\left(u_{\text {rel }}>0\right.$ above $6 \mathrm{~km}$ in Fig. 4c) and subsidence associated with the low-frequency GWs discussed in the introduction. The mid- and lower-tropospheric cooling occurred because of surface and atmospheric radiative processes as well as the lifting associated with the $n=2$ lowfrequency GW mode, which was also largely responsible for the increase in absolute humidity seen between 2 and $4 \mathrm{~km} \mathrm{AGL}$ forward of the storm (Fig. 4b). This is F02's cool and moist tongue. The resulting deepening of the preexisting layer of high humidity located around the $2-\mathrm{km}$ level rendered the environment even more conducive to convection and established a shallow layer 


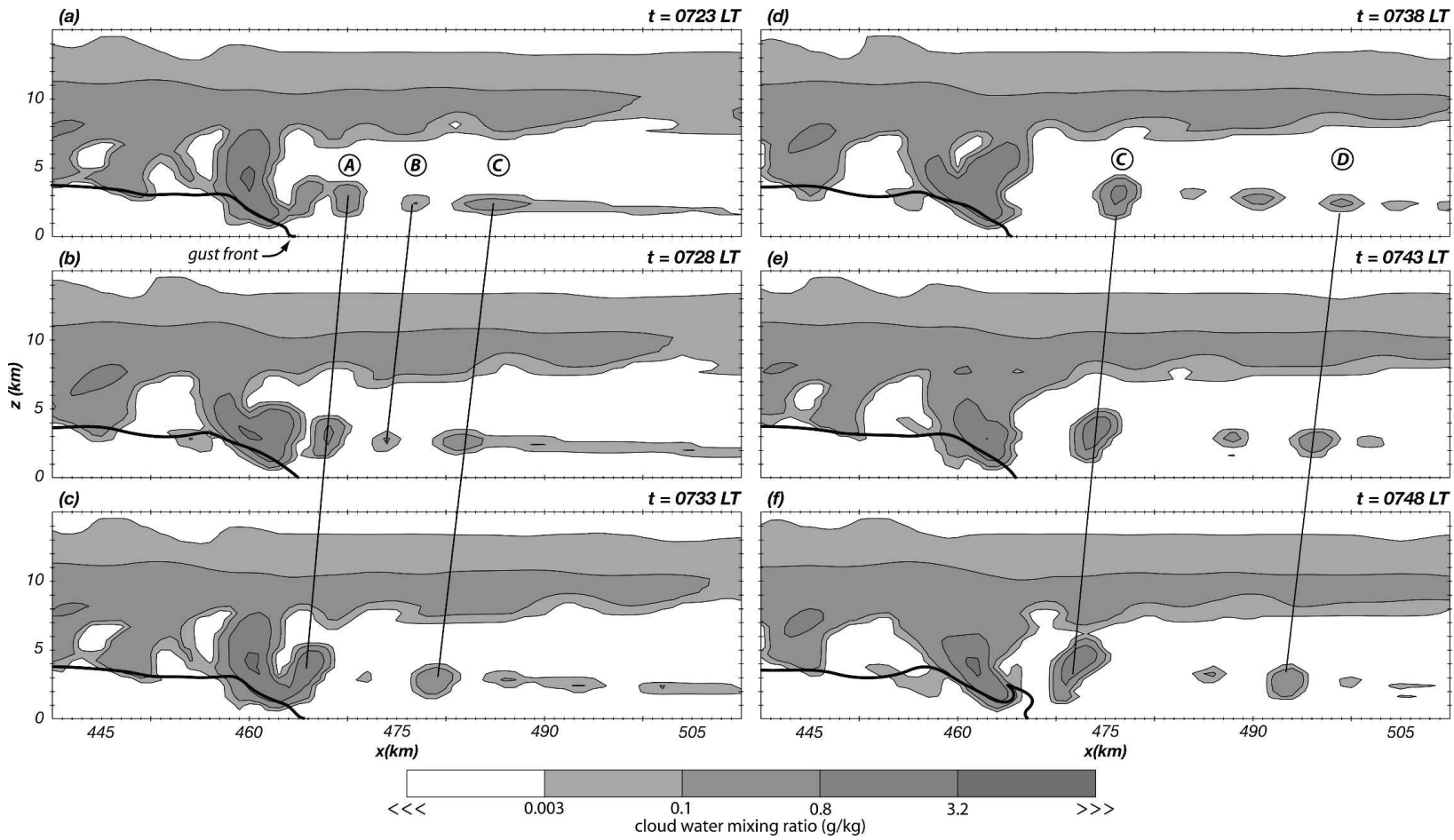

FIG. 5. Cloud water mixing ratio $q_{c}$ field, for 6 times during the control $2 \mathrm{D}$ simulation. As in Fig. 4, transformation emphasizing smaller condensate mixing ratios has been used clouds labeled A, B, C, and D are discussed in the text. The kinematic cold pool boundary is superposed.

of cloud extending ahead of the storm. Note the mixing ratios in this lower-tropospheric cloud deck were very small, and that this feature was rarely spatially continuous in instantaneous fields. Vertical profiles of temperature and relative humidity representative of the storm's forward environment are also shown in Fig. 3.

\section{b. Forward CI and GWs}

In the simulation under examination, the development of new precipitating cells in the established storm's forward environment commenced with the appearance of positively buoyant convective clouds within the shallow cloud deck. Figure 5 presents the cloud water $q_{c}$ field at 5 -min intervals starting at $0723 \mathrm{LT}$. The chosen color table emphasizes smaller condensate mixing ratios, to highlight the existence of shallow clouds as well as the initial growth phase of those clouds that became positively buoyant. As a result, at least some of the cloudiness depicted on this and some subsequent figures may be subvisible.

At the first time shown, several clouds at varying stages of development, centered between 2 and $3 \mathrm{~km}$ AGL, are seen arrayed east of the surface gust front position indicated on the figure. The cloud nearest to the gust front, above $x=465 \mathrm{~km}$ in Fig. 5a, was established by cold pool lifting as less dense air commenced rising above the cold outflow. The next three clouds to the east-labeled A, B, and C-appeared within the forward environment cloud deck noted in Fig. 4b. Each of these three features was positively buoyant at this time, translating with the embedding flow eastward with respect to the ground, but progressing westward relative to the storm and reference frame.

These three clouds represent the range of behaviors and evolutions seen among developments in the forward environment. Cloud A became established a few minutes earlier, about $13 \mathrm{~km}$ ahead of the gust front. This cloud developed further during the next twenty minutes, but did not become an independently precipitating entity prior to being assimilated by the oncoming storm around 0738 LT (Fig. 5d). In contrast, cloud C became positively buoyant farther in advance of the squall line, and thus had more time to develop prior to encountering the main line. This cloud caused a discrete propagation event at 0753 LT (Fig. 2), and figures introduced later will show it had a significant negative impact on the established storm's strength. Finally, development B was positively buoyant for a short time, but failed to develop further and it dissipated during the time period shown.

These clouds appeared in an environment through which high-frequency GWs, propagating away from the 

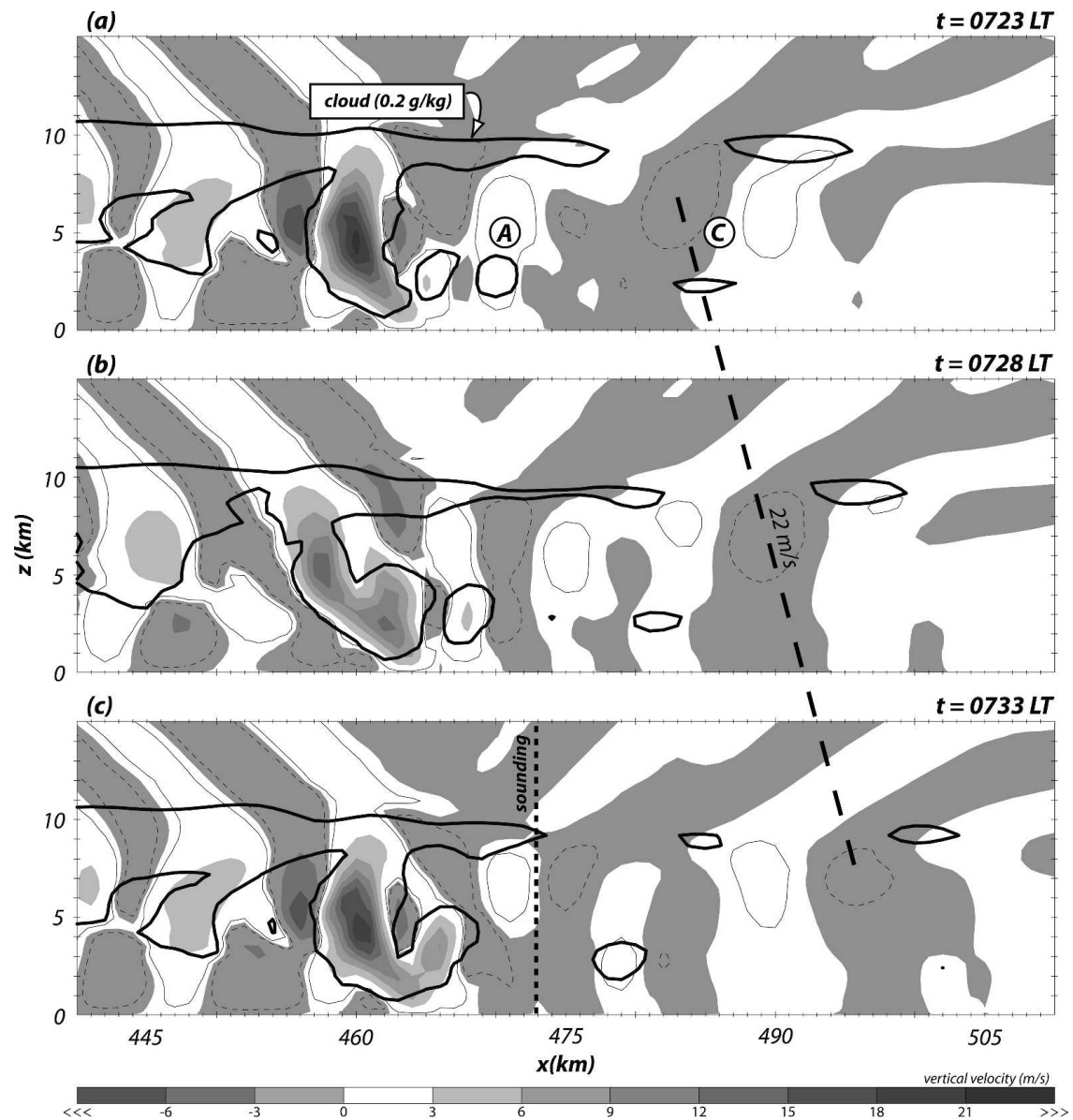

FIG. 6. Vertical velocity $w$ field for first 3 times shown in Fig. 5. Contours of $w \pm 0.5 \mathrm{~m} \mathrm{~s}^{-1}$ and the $0.2 \mathrm{~g} \mathrm{~kg}^{-1}$ cloud water outline are superposed. The location of sounding shown later in Fig. 12 is indicated. Clouds labeled A and C are discussed in the text; cloud B is absent at the chosen cloud water threshold.

storm, traveled. Figure 6 presents the vertical velocity field for the first 3 times covered in Fig. 5. Several weak yet vertically extensive updrafts and downdrafts can be seen in the environment forward of the gust front, occupying the bulk of the troposphere and propagating to the east. The frame-relative phase speed of these features is roughly $22 \mathrm{~m} \mathrm{~s}^{-1}$; this is about $36 \mathrm{~m} \mathrm{~s}^{-1}$ relative to the ground. The phase lines of these features are more or less vertically oriented in the middle troposphere, bending sharply above about $9 \mathrm{~km}$ as well as below about $3 \mathrm{~km}$. These phase line orientation changes occurred in saturated layers. The uppertropospheric saturation resides within the storm's forward anvil outflow. The relative humidity around the 2-km level was high in the initial sounding (Fig. 3), and increased during the simulation owing to radiative cooling as well as the lifting associated with the lowfrequency $n=2$ response mentioned in the introduction (see also Fig. 4b).
The early evolution of cloud $\mathrm{C}$ and failed development B is tracked in Fig. 7, which zooms in on a narrow subdomain encompassing both clouds and captures the six minute period immediately preceding Fig. 5a. The contoured and shaded field is vertical velocity $w$, with superposed cloud water contours again chosen to emphasize small condensate mass contents. A series of updrafts and downdrafts with roughly vertical phase lines can be seen that are progressing eastward, away from the established storm. The extrema of these trapped GWs fall between 5 and $7 \mathrm{~km} \mathrm{AGL}$, but the drafts extend down to the surface, modulating the shallow cloud deck. Cloud B got its start a few minutes earlier, as a GW updraft passed by its location. However, during the time period depicted, the positively buoyant cloud $\mathrm{B}$ came under the influence of a $\mathrm{GW}$ downdraft as it drifted toward the storm; this is likely why its growth ceased and dissipation ensued.

Cloud $\mathrm{C}$, on the other hand, received more favorable 

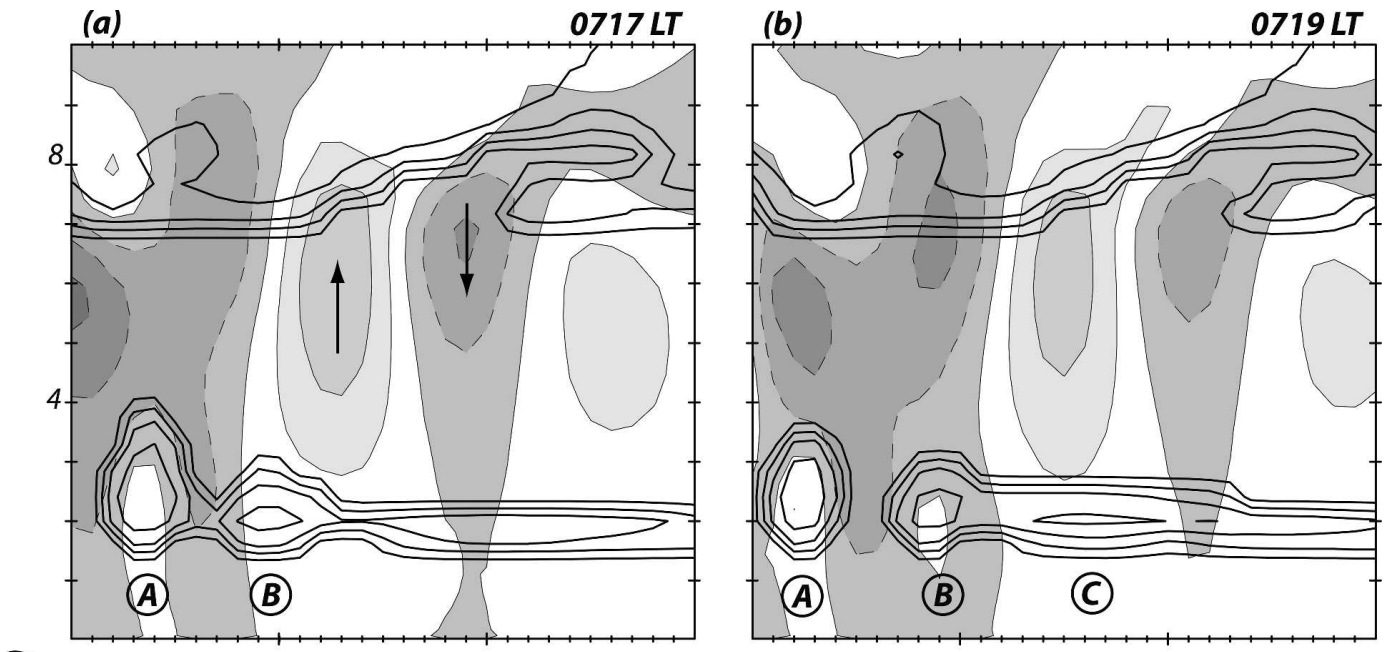

$\underset{\text { N }}{\underline{\text { E }}}$
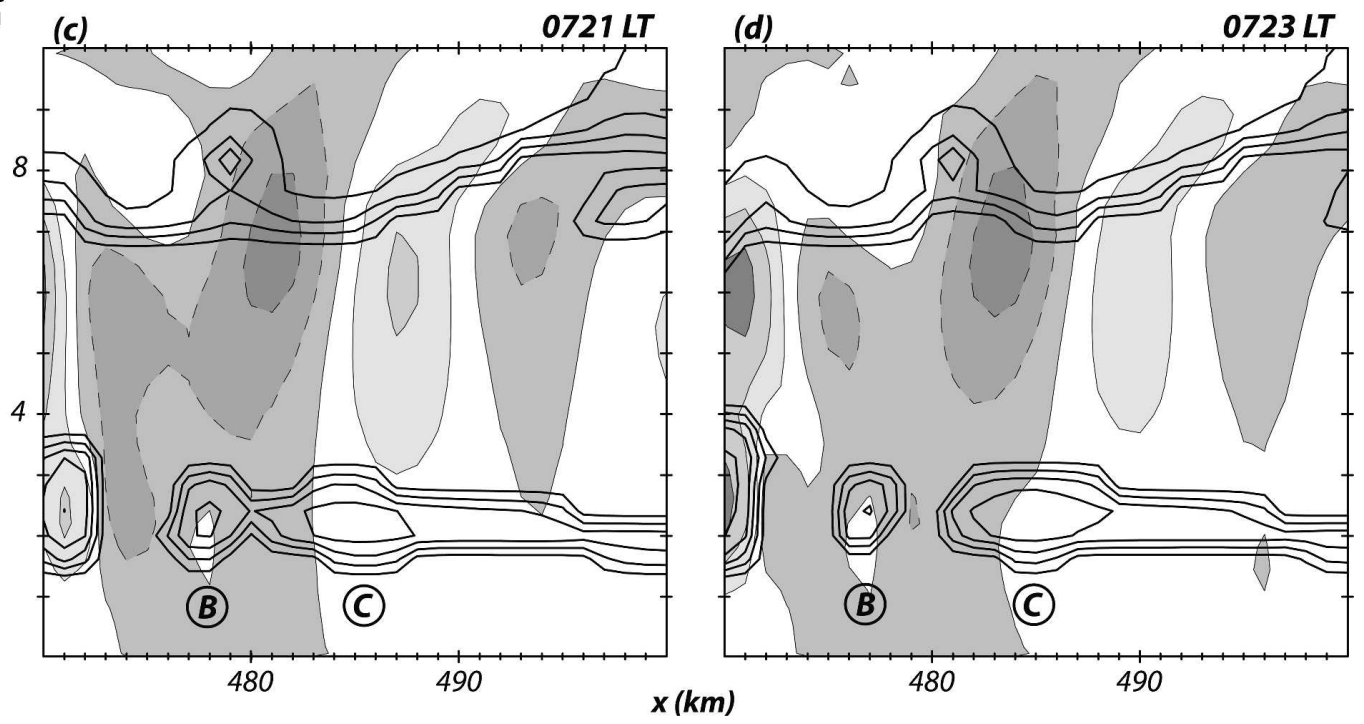

FIG. 7. Vertical velocity (shaded and contoured) fields for a subdomain in the established storm's forward environment, leading up to the first time shown in Fig. 6. Superposed field is cloud water transformed as in Fig. 4, with contour interval 0.25 . Thus, actual cloud water mixing ratios contoured include $0.0001,0.0031$, and 0.024 $\mathrm{g} \mathrm{kg}^{-1}$, etc. Clouds labeled $\mathrm{A}, \mathrm{B}$, and $\mathrm{C}$ are discussed in the text.

support from these transient waves. ${ }^{1}$ It appeared from within the shallow cloudiness around 0718 LT (above $x=489 \mathrm{~km}$ in Fig. 7b), as a GW updraft started passing by. Rapid growth ensued during the wave-associated ascent phase (Figs. 7b,c), so the cloud was fairly well established by the time it encountered a GW downdraft (Fig. 7d). Subsequent evolution of this cell into a precipitating cloud is revealed in Fig. 8, where a uniform

\footnotetext{
${ }^{1}$ Though the GWs that helped create them are clearly well represented on the grid, the clouds themselves may be a little under-resolved. This may not be optimal, but we are confident the essential physics of the process we describe is robust.
}

cloud water contour interval $\left(0.4 \mathrm{~g} \mathrm{~kg}^{-1}\right)$ is used and the shaded areas represent rainwater mixing ratios exceeding $0.1 \mathrm{~g} \mathrm{~kg}^{-1}$.

By 0743 LT (Fig. 8b), small amounts of rainwater (beneath the threshold used for shading) already existed and evaporated beneath cloud C, cooling the air in the identified region. The more substantial cooling occurring later created a cold pool that, in merging with the cold outflow from the established convection, put the gust front about $4 \mathrm{~km}$ farther east than it otherwise would have been by 0753 LT (Fig. 8c). This corresponds to the discontinuous shift in the gust front location seen in Fig. 2 around this same time, the surface signature of 

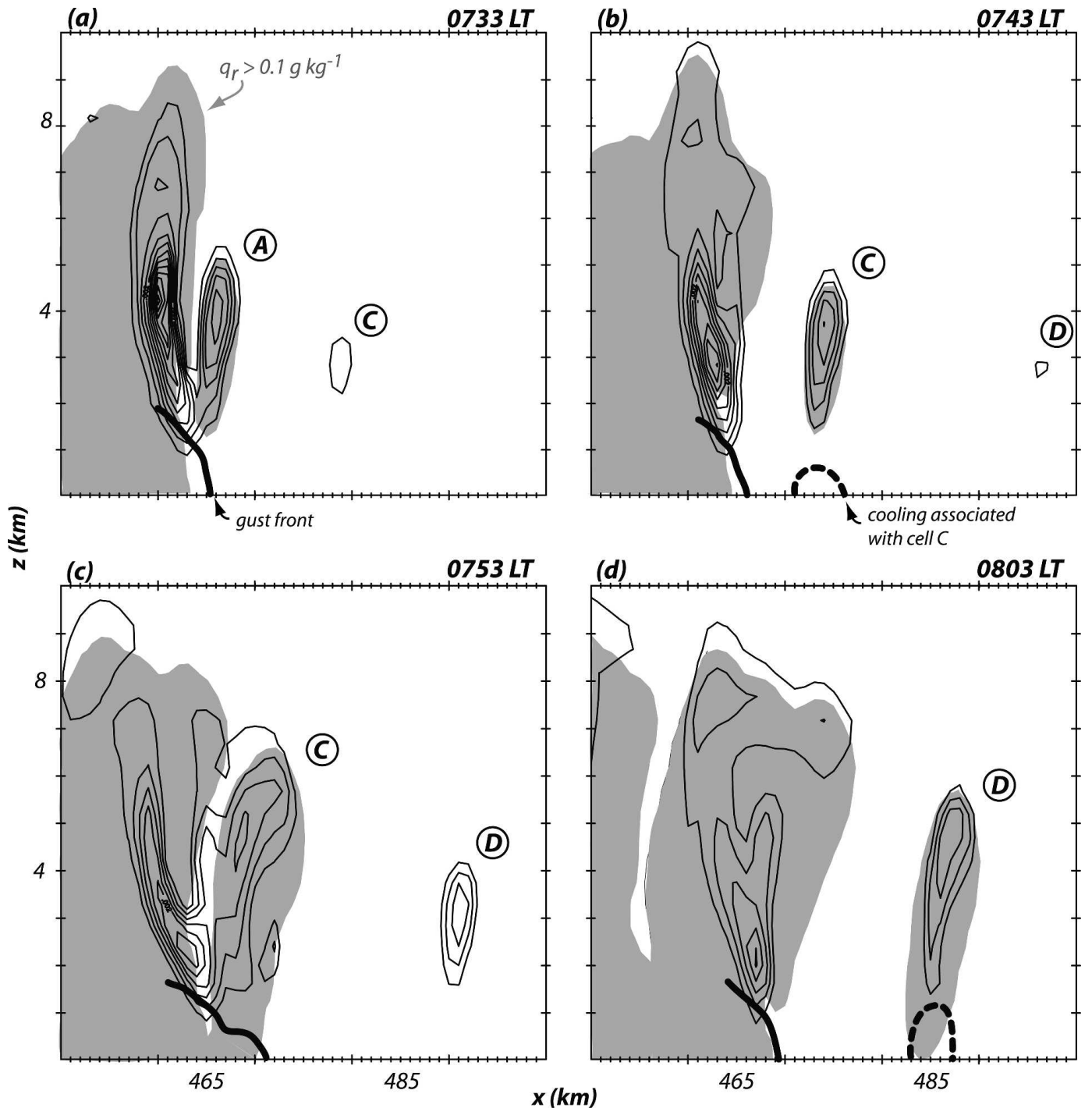

Fig. 8. Cloud water (contour interval $0.4 \mathrm{~g} \mathrm{~kg}^{-1}$ ) fields for a subdomain in the established storm's forward environment, tracking the development of precipitation in clouds $\mathrm{C}$ and $\mathrm{D}$. The shaded area denotes rainwatermixing ratios exceeding $0.1 \mathrm{~g} \mathrm{~kg}^{-1}$. Thick dashed lines delineate areas experiencing evaporation cooling associated with these cells; the established storm's gust front is identified with thick solid lines. Note cloud water field is not transformed as in Figs. 4 and 7.

a discrete propagation event. Cloud C's cold pool was not very dense, and while it spread eastward relative to the ground (note dashed arrow in Fig. 2), it propagated less rapidly than the established storm's outflow, which was able to catch up. We will show in section $3 \mathrm{~d}$ that this new cloud exerted a significant impact on the established storm and the forward environment. The last two panels also capture the appearance of yet another new cell, designated $\mathrm{D}$, which was initiated and began precipitating even farther upstream than cloud C. That development was associated with the even more dramatic discrete propagation event that occurred shortly after 0800 LT (Fig. 2).
The general influence of these waves on the cloudiness in the forward environment is revealed in Fig. 9, a Hovmöller diagram of cloud water (shaded) and vertical velocity (contoured) spanning a time period from earlier in the simulation. The cloud water field was vertically integrated only through the lowest $3 \mathrm{~km}$ to capture the cloud deck and exclude the forward anvil. The vertical velocity field was averaged between 4 and $7 \mathrm{~km}$ to roughly capture the horizontally propagating GWs. The thick solid line indicates the surface gust front position.

The first thing noticed is that the cloud deck ahead of the line was neither uniform nor stationary in any ref- 


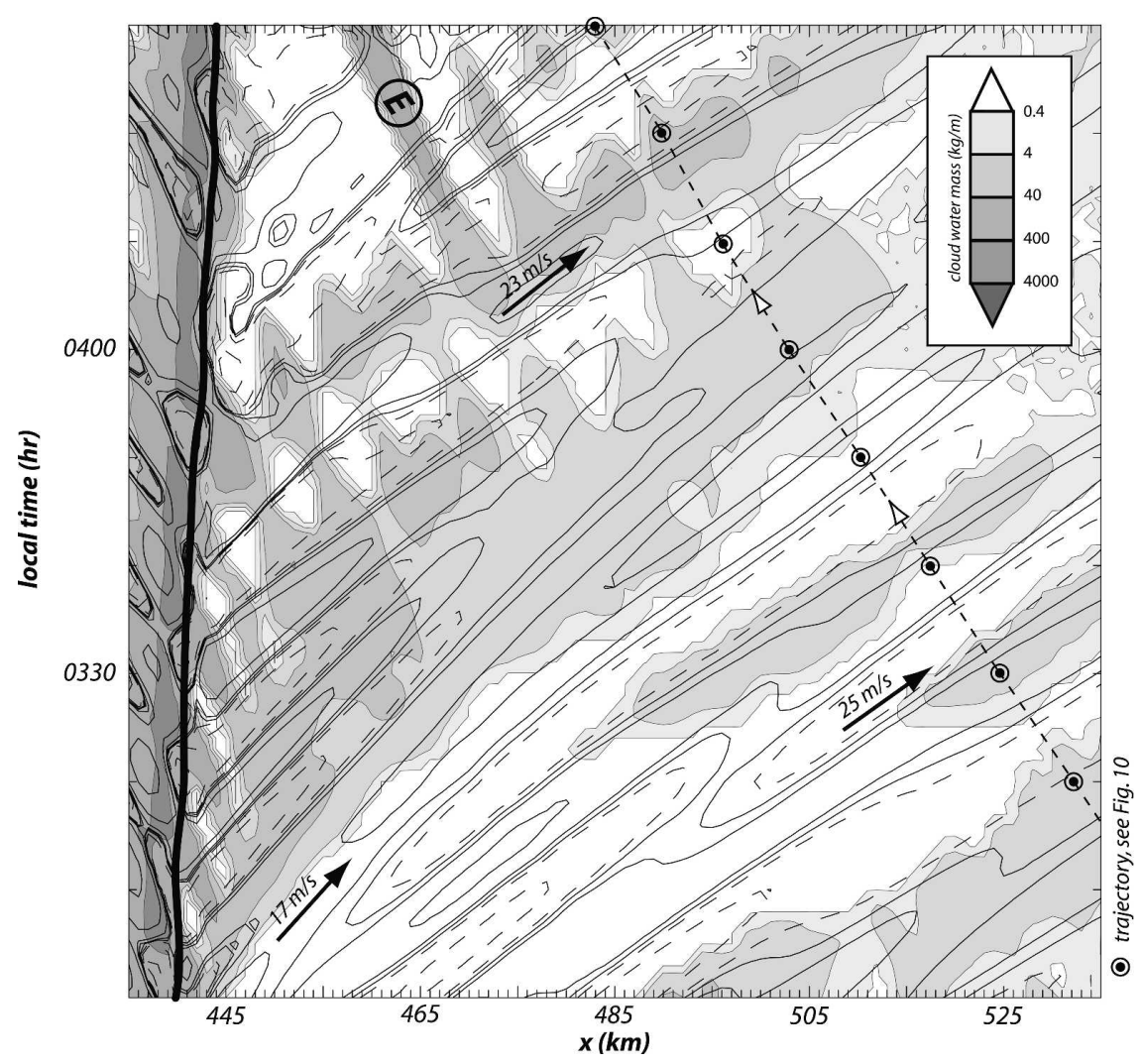

FIG. 9. Hovmöller diagram showing 0-3-km cloud water mass (shaded) along with contours of vertical velocity $w$ averaged between 4 and $7 \mathrm{~km}$ AGL. Contours shown for $w$ are \pm 0.2 , $\pm 0.8, \pm 3.2$, and $\pm 12.8 \mathrm{~m} \mathrm{~s}^{-1}$. The trajectory of the parcel tracked in Fig. 10 is superposed, as is the gust front position. The streak formed by cloud $\mathrm{E}$ is discussed in the text.

erence frame, as might have been surmised from Fig. 4b. Streaks consisting of shallow cloud originate around the gust front and translate forward of the storm at roughly $20 \mathrm{~m} \mathrm{~s}^{-1}$ relative to the reference frame $(\approx 35$ $\mathrm{m} \mathrm{s}^{-1}$ relative to the ground), though the propagation speed tends to increase with distance from the leading edge of the gust front. These streaks propagating away from the storm and into the forward environment (forward propagating) were punctuated by clearings of greater and lesser extent, which progressed through the forward environment at approximately the same speed. The local variations of cloud water content are well correlated with the updraft and downdraft bands, which also originated at the storm's leading edge. These are signatures of the forward-propagating gravity waves previously identified in Figs. 6 and 7.

Also shown in Fig. 9 is a trajectory of a parcel originating within the cloud deck well ahead of the storm, at about $1.7 \mathrm{~km}$ AGL. The parcel approached the storm at about $7 \mathrm{~m} \mathrm{~s}^{-1}\left(7.5 \mathrm{~m} \mathrm{~s}^{-1}\right.$ eastward relative to the ground), the average flow speed within the cloud deck, causing it to traverse a series of forward-propagating
GWs. Time series of cloud water and elevation for this parcel are shown in Fig. 10. Superimposed on a slow yet systematic ascent mainly because of the $n=2$ response are short period oscillations in vertical position caused by the forward-propagating GWs. The transient gravity waves clearly have the ability to modulate cloud water content, causing clearing during descent but a rebound of cloudiness during ascent. Because wave-relative flow in forward-propagating GWs is directed backward, toward the storm, wave-associated cloudiness perturbations will be in quadrature with vertical velocity, the well-recognized phenomenon (e.g., Eom 1975) illustrated in Fig. 11.

Backward-propagating cloud streaks also appear in Fig. 9, moving with the mean flow toward the storm. The streaks were mainly created by the positively buoyant clouds that formed within the shallow cloud deck. Most, if not all, of these clouds started growing because of the assist provided by the high-frequency gravity wave updrafts, but soon started moving independently from those waves. Many of those streaks are short, indicating new, discretely initiated convective develop- 


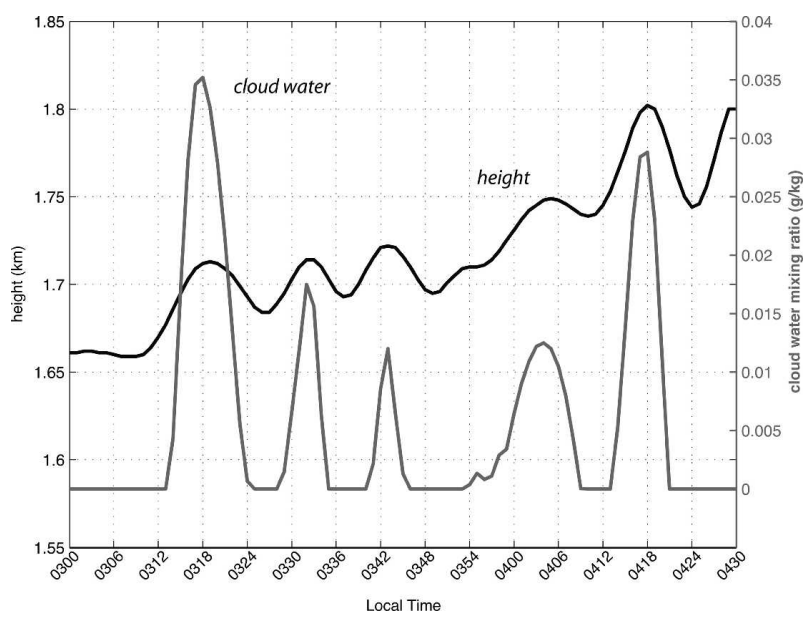

FIG. 10. Time series of height (black line) and cloud watermixing ratio (gray line) for the parcel whose trajectory was shown in Fig. 9.

ments that failed to develop further. In numerous cases, the streaks ended when the clouds encountered a GW downdraft. However, some of the new elements-like development A examined above-survived to exert a substantial impact on the established squall line. One such development appearing on the figure is labeled E; this cloud was involved in the discrete propagation event that occurred around 0500 LT in Fig. 2.

\section{c. Ducting of the GWs in the forward environment}

In this simulation, the forward-propagating highfrequency GWs played a critical role in forward CI leading to discrete propagation. These waves provide the spark that is often missing in other simulations. GWs are ubiquitous in both actual and simulated nature; the storm is a ready source of both short and long period heating and momentum variations that provoke the surrounding environment, necessitating the kind of adjustment that GWs accomplish. The low-frequency GWs, such as the $n=2$ response previously mentioned, are nearly hydrostatic (e.g., Bretherton and Smolarkiewicz 1989; Mapes 1993) and thus not vertically propagating; ducting or trapping is not needed to keep their energy in the troposphere. However, their highfrequency counterparts are vertically propagating, and can quickly pass into the stratosphere (e.g., Fovell et al. 1992; Alexander and Holton 2004). Most idealized simulations of organized convection in $2 \mathrm{D}$ and $3 \mathrm{D}$ appear to possess relatively quiescent tropospheric forward environments during maturity, free of the kind of short-period activity seen in this control run (e.g., Figs. 6-9). Indeed, even the waves seen in the present case would not exist without some kind of containment mechanism.

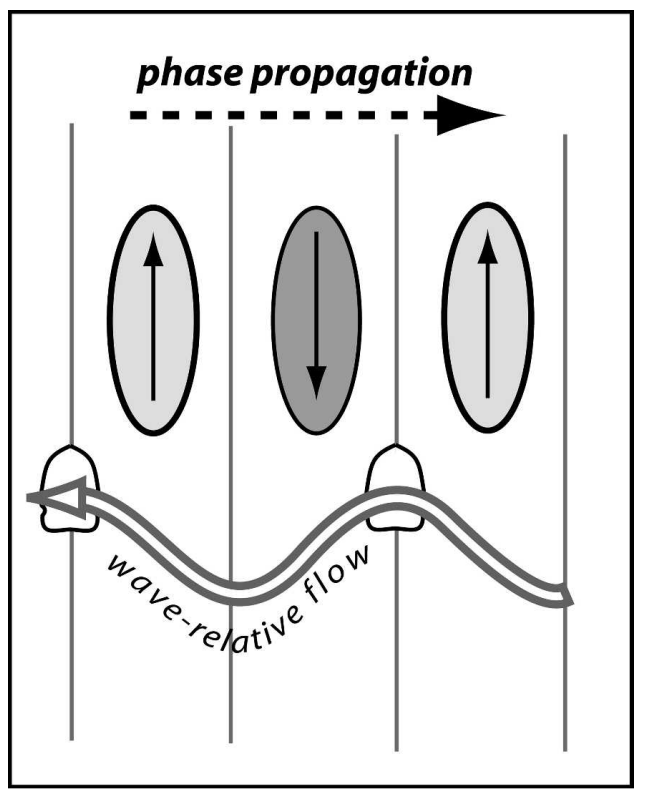

FIG. 11. Schematic illustrating the influence of gravity waves on a parcel moving with the mean flow.

The high-frequency GWs appear to be partially trapped by, and ducted beneath, the forward anvil outflow. It is possible that this same mechanism was operating in Tripoli and Cotton's (1989a,b) case. This is reminiscent of the wave trapping in the storm's trailing region discussed in Yang and Houze (1995), who explained that phenomenon using the Scorer parameter $l^{2}$ (Scorer 1949; Crook 1988), approximated as

$$
l^{2} \approx \frac{N_{*}^{2}}{(U-c)^{2}}-\frac{U_{z z}}{(U-c)} .
$$

In the above, $N_{*}$ is the subsaturated $(N)$ or saturated $\left(N_{m}\right.$; Durran and Klemp 1982) Brunt-Väisällä frequency, and $U$ is the storm-relative wind with $U_{z z}$ being its second derivative with height, revealing the wind profile's curvature. The parameter also depends on the phase speed $c$ of a given wave. A wave with horizontal wavelength $L_{x}$ and wavenumber $k=\left(2 \pi / L_{x}\right)$ will be vertically propagating if $k^{2}<l^{2}$ and decaying for $k^{2}>$ $l^{2}$. Thus, a layer with small values of the Scorer parameter overlying one with large values will cause reflection, effectively trapping at least some waves. If $l^{2}<0$ at some height, all vertically propagating waves originating below that level will be trapped.

Figure 12 presents vertical profiles of $U, N_{*}^{2}$, and $l^{2}$ at the location shown in Fig. 6c. These profiles pass through a GW downdraft and a gap in the cloud deck. The phase speed used in the calculation was $22 \mathrm{~m} \mathrm{~s}^{-1}$, roughly the storm-relative motion of forward-propagating GWs identified in Figs. 6 and 9. The figure re- 


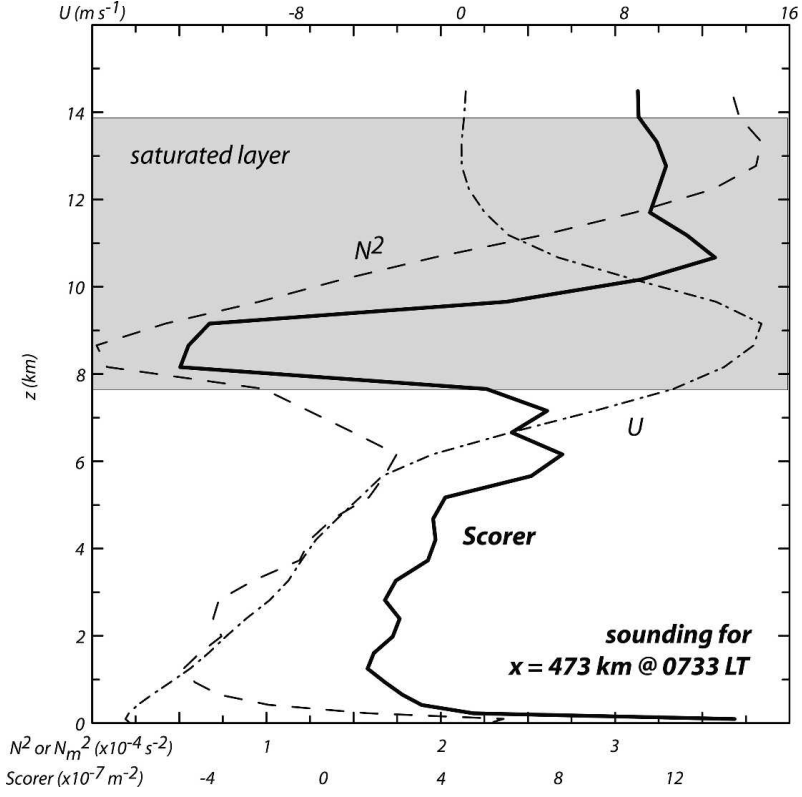

FIG. 12. Sounding in the storm's forward environment (at location identified in Fig. 6c) showing storm-relative horizontal velocity $U$, square of subsaturated or saturated Brunt-Väisälä frequency $\left(N^{2}\right.$ or $N_{m}^{2}$, respectively), and the Scorer parameter, based on $22 \mathrm{~m} \mathrm{~s}^{-1}$ phase speed.

veals that the forward anvil base served as an effective duct for this wave, with both terms in (1) contributing to the creation of sharply lower $l^{2}$ values there. The greatly reduced stability and large negative curvature shear in the anvil led to negative $l^{2}$ values just above the anvil base. Note that because $U<c$ everywhere, the profile lacked a critical level for this wave. However, the fact that the magnitude of $(U-c)$ was relatively small in the forward anvil, above the duct, suggests that other trapping mechanisms discussed in Lindzen and Tung (1976) may also have been acting. The bottom line is that, at least in the simulations we have examined, model storms lacking substantial forward anvils have little or no tropospheric high-frequency GW activity out ahead of the storm and thus are lacking a forcing mechanism, which can cause CI there.

\section{d. Forward CI as a disturbance}

New forward convection-at least upon achieving a certain degree of development-represents a distur- bance to the established storm as well as their shared environment. The most immediate consequence of significant forward $\mathrm{CI}$ is the excitation of compensating subsidence that propagates away from the new convection in all directions. Part of the subsidence signal may be directed toward the established storm; Fovell (2005) showed how subsidence from a new convective cell appearing ahead of the sea-breeze front temporarily throttled convection associated with the front itself. Of interest here is the effect of the compensating descent on the environment in advance of both storms, old and new. Specifically, it is found that significant forward CI temporarily suppresses the cool and moist tongue, the shallow cloud deck eventually rebuilding in its wake. A consequence of this is forward $\mathrm{CI}$ in this case tends to be episodic, punctuated by quiescent periods.

An example of this is provided by Fig. 13, which documents the interruption and reestablishment of the cool and moist tongue that follows the discrete propagation event that occurred around 0500 LT (see Fig. 2). That event was associated with cloud previously designated E (Fig. 9), which was in the process of rapid development at the time of Fig. 13a. Soon thereafter, deep subsidence appeared, translating eastward away from the storm; the location of maximum descent is indicated by the downward pointing arrow on the last four panels. The phase speed of this subsidence was roughly $33 \mathrm{~m} \mathrm{~s}^{-1}$ relative to the ground, comparable to that of the high-frequency GWs traversing this environment. However, there are contrasts with the highfrequency GW downdrafts: the subsidence was typically twice as intense, was concentrated lower in the troposphere, and possessed a marked tendency to expand horizontally as it propagated, this dispersive behavior suggesting the existence of several convolved waves. The subsidence itself is manifested in this figure by the negative water vapor perturbations (shaded field) established in its wake, and the concomitant disappearance of the cloud deck (dashed contours). While this transpired, the established storm approached the new development and finally overtook it.

The subsequent reestablishment of the cool and moist tongue and its cloud deck appears to be a more complex phenomenon, but it commenced with the appearance of a deep GW updraft following the subsi-

FIG. 13. Water vapor perturbation fields following the development of cloud E (see also Fig. 9), which caused the discrete propagation event around 0500 LT (Fig. 2). Shaded contours of water vapor perturbation fields are emphasized with thin contours showing areas of positive (solid) and negative (dashed) perturbations. Thick solid (dashed) contours represent cloud water mixing ratios of 0.2 (0.01) $\mathrm{g} \mathrm{kg}^{-1}$. Solid arrows indicate positions of maximum subsidence and ascent following the appearance of cloud E. Dashed upward arrows indicate additional ascent involved in rebuilding the cool and moist tongue (see the text). There are other downdrafts and updrafts in the forward environment not identified in the figure. 

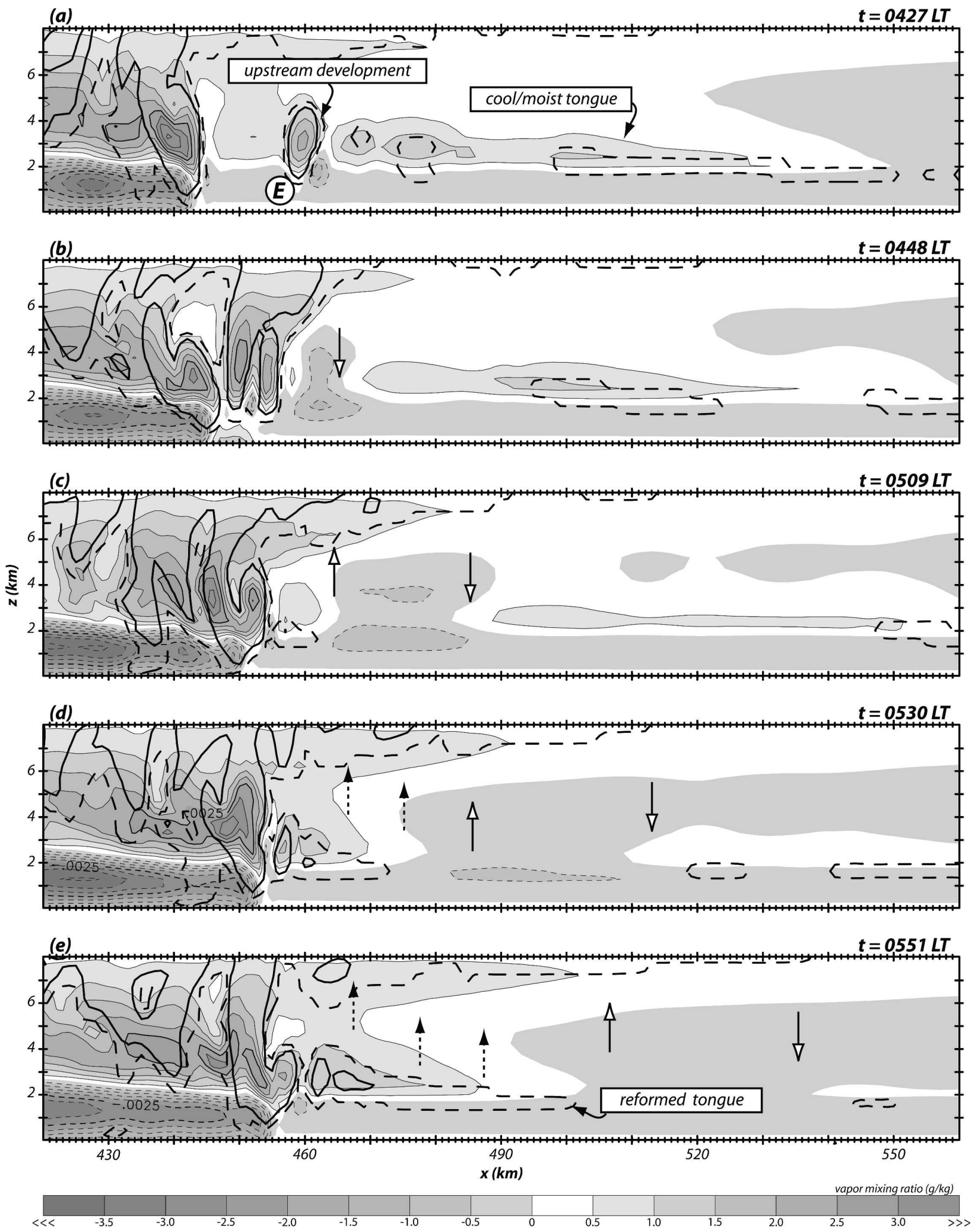
dence wave after some time interval. This ascent appears to undo a large part of the local drying caused by the compensating subsidence; the location of largest ascent in the wave is indicated by the white, upwardpointing arrow. This deep ascent was followed by a succession of somewhat shallower and slower moving updrafts, indicated in the figure with the dashed arrows, which acted in concert to bring the air in the lower to midtroposphere progressively closer to saturation. The origin of, and impetus for, these updrafts is not immediately clear, and is the subject of future work. However, the end result was the restoration of the cloud deck (Fig. 13e), setting the stage for future forward CI episodes.

\section{e. Sensitivity tests}

The majority of idealized cloud model simulations we have made evince no forward CI. A number of sensitivity tests, involving model physics and microphysics, geometry, and initial conditions, were conducted to elucidate the reasons why the control run was so susceptible to this phenomenon. The following aspects of the control simulation were determined to be favorable to the occurrence of forward CI.

1) The forward anvil and the upper-tropospheric winds, molded into a jetlike profile by the squall line's circulation.

2) The shape of the convective region's heating profile, responsible for exciting the low-frequency gravity wave mode that established the convectively favorable cool and moist tongue, which increased the relative humidity of the lower troposphere. This sensitivity is explored in Fovell (2002) and will not be discussed further here.

3) Radiative processes that affect the temperature and relative humidity of the surface and free troposphere.

The first aspect is relevant to the trapping and ducting of the high-frequency GWs. There are two ways of getting a stronger anvil outflow, either by making the storm more intense, which may involve increasing the low-level shear (e.g., Rotunno et al. 1988; Fovell and Ogura 1989; Weisman and Rotunno 2004), or by deepening the shear layer (e.g., Fovell and Dailey 1995). In varying the shear layer depth, Fovell and Dailey (1995) found that while the mid- to upper-tropospheric shear had little influence on overall convective intensity, more deeply sheared storms possessed more extensive anvils (see their Fig. 3). A simulation with an equally strong but shallower westerly shear layer resulted in a strong squall line that possessed a much less extensive forward anvil outflow, so GWs were not trapped. In that case, the relative humidity in the forward environment was as high as in the control run, but the spark was missing, and so the shallow cloud deck stretching ahead of the storm went undisturbed.

The presence of GWs is not a sufficient condition, however. When surface and atmospheric radiative processes were excluded from the control run, no forward CI occurred. That case had a well-developed cool and moist tongue but the cloud deck was much less extensive, and the GW updrafts were unable to lift any parcels to positive buoyancy. In this study, the extra cooling associated with radiation, and the small increase in relative humidity that resulted, made the difference between forward CI and its absence. The general conclusion is that in order for high-frequency GWs to encourage CI, the lower-tropospheric humidity has to be close to saturation already.

Sensitivity to model geometry and cloud microphysics was also assessed. Figure 14 shows horizontal cross sections of vertically integrated cloud water, again restricted to the lowest $3 \mathrm{~km}$ and transformed to highlight small values, from a 3D simulation employing the commonly used South Dakota ice scheme (e.g., Lin et al. 1983), initialized as described in section 2. In Fig. 14a, the band possessing small cloud water content located at $x=425 \mathrm{~km}$ was associated with lifting by a trapped GW. Several positively buoyant clouds, including the two highlighted in Fig. 14b, appeared as the band translated farther ahead of the storm. These new convective elements were advected toward the established storm, ultimately merging with it after the final time shown in the figure. It is clear the results appear qualitatively very similar to their $2 \mathrm{D}$ and ice-free counterparts, including the occasional discrete propagation episode.

\section{Discussion and summary}

Herein, numerical cloud model simulations of squall lines were examined to study examples of forward CI. Here, the storm's forward environment is defined with respect to the storm's propagation direction (see the introduction), so forward CI refers to the establishment of new positively buoyant cumulus clouds in advance of an established line. Because the evaporationally induced subcloud cold pools of most storms spread faster than the lower-tropospheric winds, a squall line may catch up with new convective developments in the forward environment translated solely by advection. The new clouds themselves may not reach the precipitating stage prior to encountering the established line, but if they do, they can generate their own cold pools and injure the established storm, perhaps by blocking the 

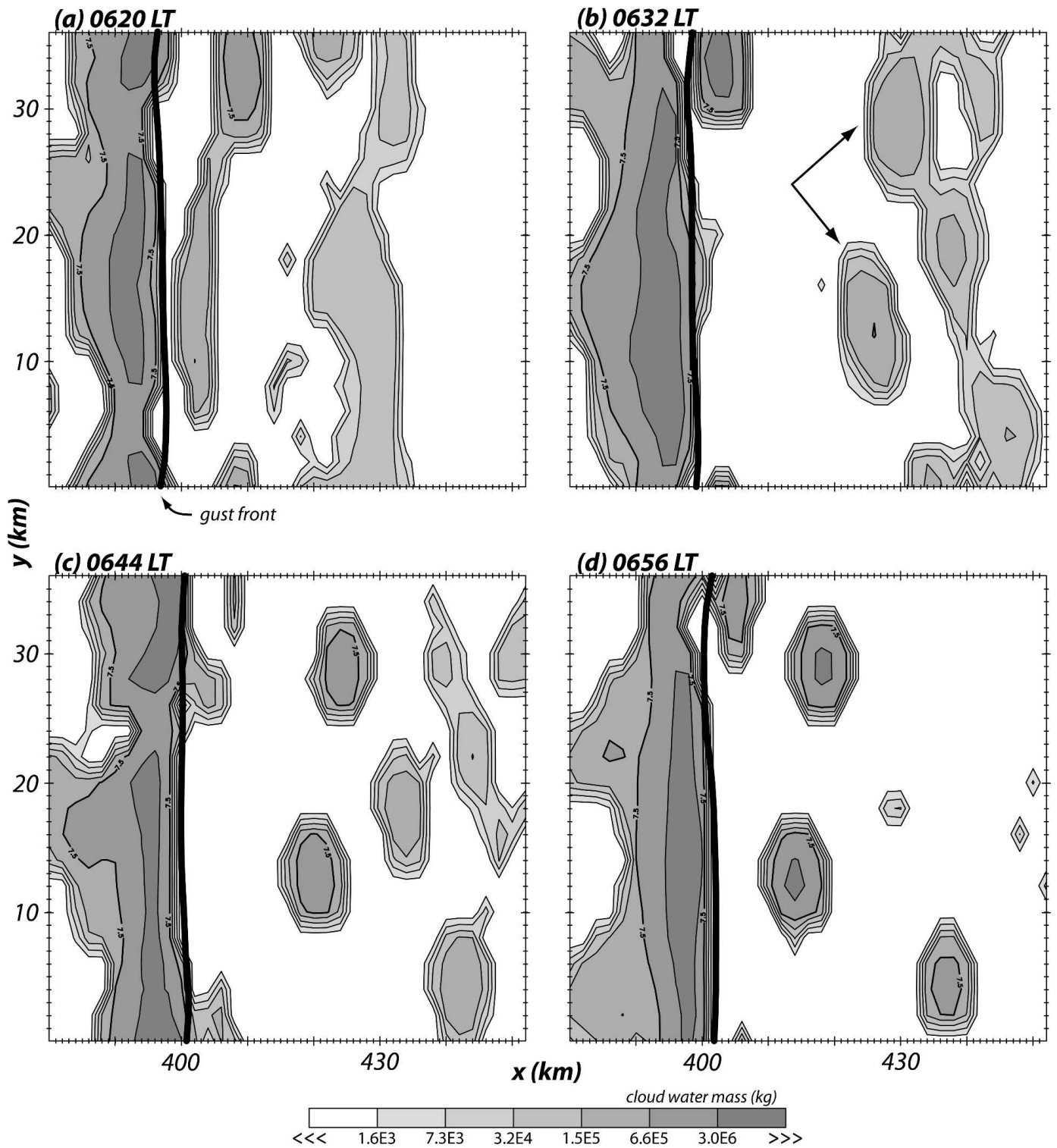

FIG. 14. Horizontal cross sections of $0-3-\mathrm{km}$ cloud water mass $(\mathrm{kg})$ from a 3D simulation with ice microphysics. Logarithmic transformation was applied to highlight small values. The surface gust front position is shown as a thick black contour. Note the aspect ratio is not $1: 1$. Only a portion of the domain is shown.

latter's inflow and/or by provoking subsidence in its vicinity. In any event, the episodic appearance of new convective cells in advance of an established storm can effectively increase the propagation speed of the storm complex, resulting in what is often referred to as discrete propagation (e.g., Zipser 1977; Houze 1977, 2004).

The key assumption is that the new developments appear sufficiently close to an existing storm to infer causality, while precluding mechanical cold pool lifting. In this situation, an action-at-a-distance mechanism involving the established storm is necessary. We found that internal GWs, excited by temporal variations of convective activity in the squall line, could provide such a mechanism. For this concluding discussion, we review the consequences and particulars of this mechanism with the aid of two summary figures.

In a sense, Fig. 2 contained no more information than a basic weather radar scan targeting precipitation-sized particles; occasionally, new discrete echoes suddenly appeared, seemingly from nowhere, in advance of a organized storm and its gust front. The preceding analysis, however, revealed that there may be a lot of activity in the established storm's forward environment 


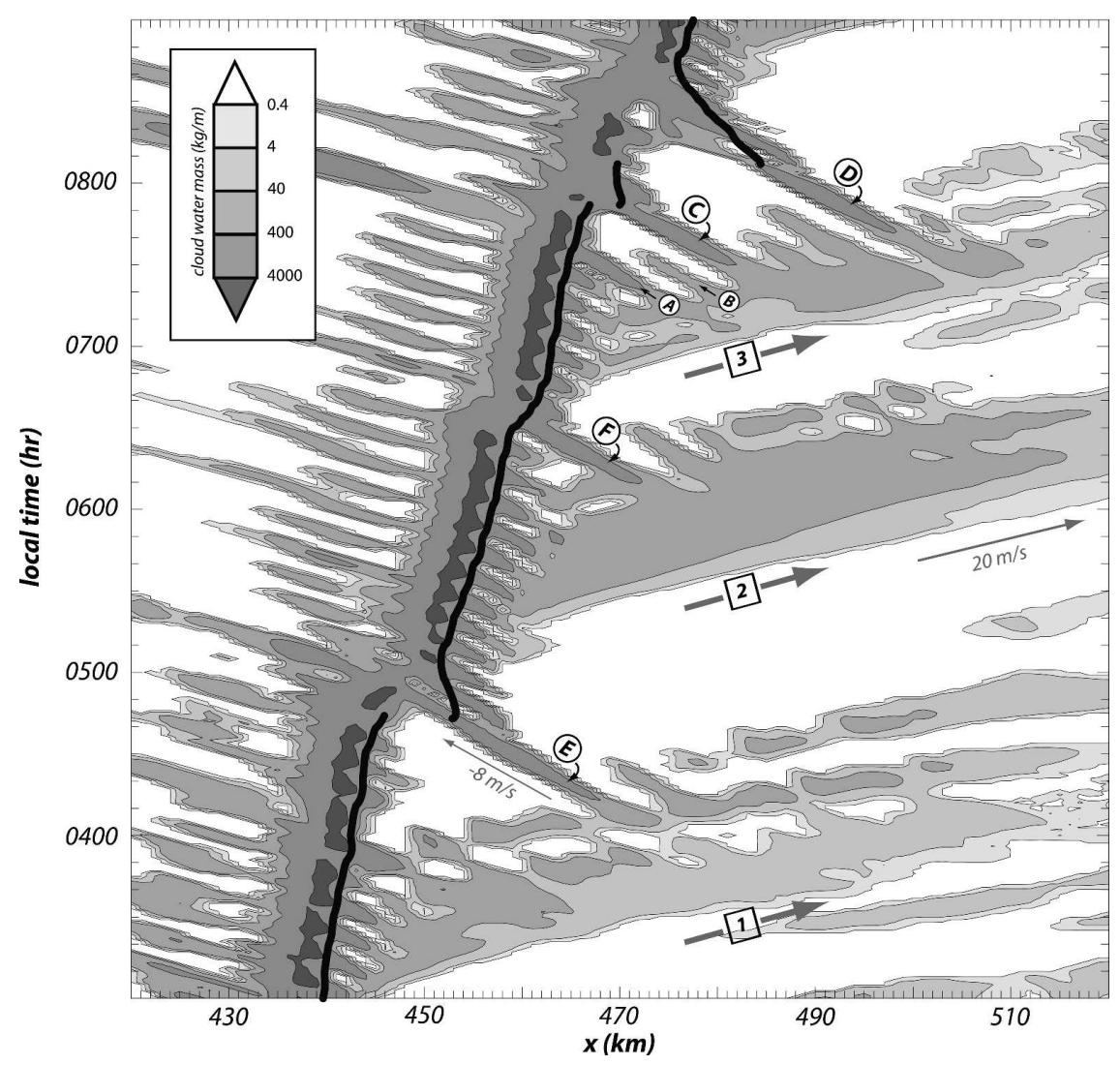

FIG. 15. Same as in Fig. 2, but showing cloud water mass, vertically integrated between the surface and $3 \mathrm{~km}$. The surface gust front location is again superposed. Streaks associated with clouds discussed in the text are labeled in the figure.

that might elude detection by a single observing instrument. In the control run, that activity was associated with high-frequency GWs trapped by the forward anvil, a cool and moist tongue of finite extent associated with longer-period environmental adjustments, a shallow layer of cloud in which new cumulus clouds can form and grow, and intermittent deep subsidence provoked by forward convective initiation.

Much of that activity is seen directly or indirectly in Fig. 15, another Hovmöller diagram spanning the same subdomain and time period as in Fig. 2, but presenting vertically integrated cloud water mass in the lowest 3 $\mathrm{km}$, a longer view than that afforded by Fig. 9. From this expanded view, forward-propagating streaks consisting of small cloud water contents are easily seen, aggregated into the bands labeled $1-3$ in the figure. Those streaks make visible the forward-propagating internal GWs that were excited at the established storm's leading edge (Figs. 6 and 9), their vertical motions locally enhancing or suppressing the shallow cloud deck as they passed through. Frequently, the GW updrafts kicked off new cumulus clouds that achieved some de- gree of positive buoyancy and propagated toward the storm in this reference frame (Fig. 7); these are the backward-translating streaks originating within the forward-progressing cloud bands. The ground-relative motion of these new clouds was in the same direction as the established storm, but slower, as they were borne by the winds rather than pushed by a cold pool.

Many of the backward-translating streaks are short, representing clouds that failed to retain their positive buoyancy very long. For the majority of those clouds, the CI provided by a transient GW updraft did not survive the encounter with the next GW downdraft. Those that did survive were either assimilated by the approaching storm before becoming mature cumulus clouds or reached the precipitating stage prior to merger. Typically, the former had a neutral or even positive impact on the established convection while the latter invariably weakened the main storm. If a new cell builds its own cold pool sufficiently far in advance of the original line, the parent storm may dissipate, leaving the new development as the main storm, a very obvious example of discrete propagation. 
(a)
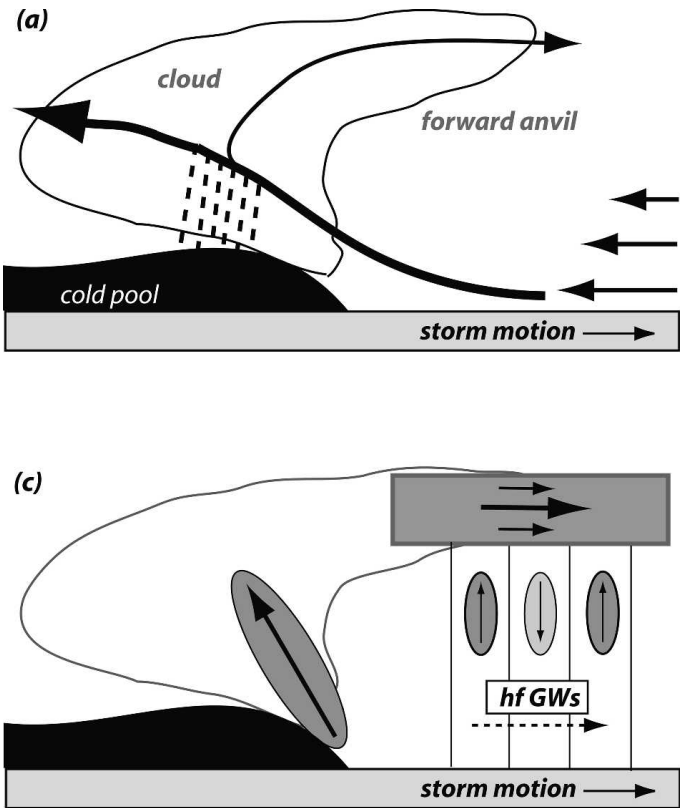

(b)
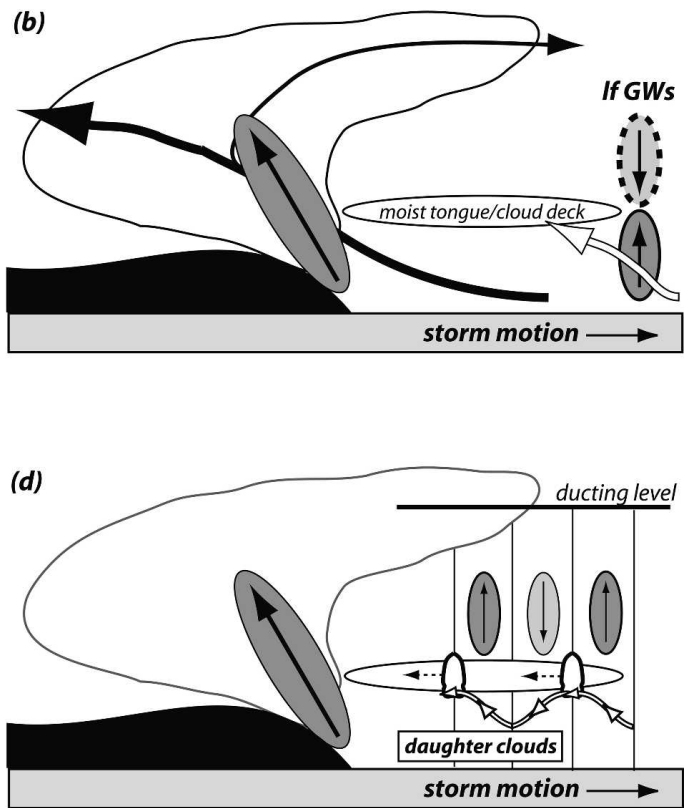

FIG. 16. Schematic description of the factors involved in the forward CI and discrete propagation events discussed in this study. See text for further information.

The impact of new forward convection on the established storm is revealed in Fig. 15 by the lowertropospheric cloud water contents just west of the gust front. Condensate totals there were typically large, but fluctuated as updrafts within the storm's convective region waxed and waned. The backward-propagating streaks labeled A-F are examples of forward CI. As already revealed in Fig. 5, development A encountered the main line prior to maturity, and Fig. 15 suggests this merger had little influence on the storm. However, the new cells labeled $\mathrm{C}-\mathrm{F}$ all evolved into precipitating storms prior to merger, and each provoked a substantial decrease in cloud water content in the parent storm. These new developments also impacted the very same forward environment in which they were initiated and grew, since the absence of cloudiness in the forward environment following a significant new development was to a large degree due to the subsidence provoked by the sudden appearance of a new heat source (cf. Fig. 13). The shallow cloud deck eventually reformed, but not before a relatively quiescent period lasting tens of minutes had passed.

We close by presenting a summary schematic in Fig. 16. The squall line's storm-relative airflow (Fig. 16a) consists of low-level inflow rising over a subcloud cold pool, with some overturning leading to the formation of the upper-tropospheric forward anvil. The forward CI seen in the control simulation required the constructive combination of three factors: the presence of relatively high humidity in the lower-tropospheric inflow, the generation of high-frequency internal GWs by the squall line, and the trapping of those waves beneath the forward anvil. The lower-tropospheric humidification was supported by the early mature phase formation of the cool and moist tongue, a consequence of lowfrequency GWs (If GWs; Fig. 16b) associated with persistent heating and cooling in the main storm's convective region. Radiative processes likely aided in the establishment of the deck of shallow cloud seen stretching ahead of the storm, coincident with the moist tongue. In the simulations examined herein, the shallow cloud deck usually contained very low cloud water contents, indicating the likelihood that the cloudiness was generally subvisible, at least prior to local episodes of forward CI.

High-frequency GWs (hf GWs), in contrast, were generated as a result of fluctuations in convective activity of the parent storm (i.e., multicellularity) and progressed through the parent storm's forward environment (Fig. 16c). These normally vertically propagating waves were ducted beneath the forward anvil's base because of the decreased stability and jetlike wind profile characteristic of the anvil. The consequence of superposing these two types of GWs is illustrated in Fig. 16d. Enhanced lifting associated with the highfrequency GW updrafts helped create positively buoyant cumulus clouds within the preexisting cloud deck. These developments, or "daughter clouds" (Browning et al. 1976; Tripoli and Cotton 1989b; Fovell and Tan 1998), were carried by the storm-relative winds toward 
the established convection, and while many were short lived, some provoked discrete propagation events.

Even in simulations in which there was a lot of activity in the storm's forward environment, it is worth remembering that idealized cloud model simulations represent something of a "clean room" environment. In reality, there are many sources of perturbations that may act to initiate-or perhaps suppress-convection in and around a storm, including gravity waves associated with distant convection or mountains, undular bores (e.g., Crook 1988), variations in topography, land surface characteristics and surface fluxes, and environmental inhomogeneities in general. The value of these experiments is in demonstrating the validity of a specific hypothesis in a relatively controlled setting. There are likely many avenues leading to forward CI, the specific mechanism discussed herein, though plausible, being just one of them.

Acknowledgments. The authors thank two anonymous reviewers for their constructive suggestions. This work was supported by NSF Grant ATM-0139284. The ARPS model was developed at the Center for the Analysis and Prediction of Storms at the University of Oklahoma.

\section{REFERENCES}

Alexander, M. J., and J. R. Holton, 2004: On the spectrum of vertically propagating gravity waves generated by a transient heat source. Atmos. Chem. Phys., 4, 923-932.

Bretherton, C. S., and P. K. Smolarkiewicz, 1989: Gravity waves, compensating subsidence and detrainment around cumulus clouds. J. Atmos. Sci., 46, 740-759.

Browning, K. A., and Coauthors, 1976: Structure of an evolving hailstorm. Part V: Synthesis and implications for hail growth and hail suppression. Mon. Wea. Rev., 104, 603-610.

Carbone, R. E., J. W. Conway, N. A. Crook, and M. W. Moncrieff, 1990: The generation and propagation of a nocturnal squall line. Part I: Observations and implications for mesoscale predictabilty. Mon. Wea. Rev., 118, 26-49.

Crook, N. A., 1988: Trapping of low-level internal gravity waves. J. Atmos. Sci., 45, 1533-1541.

— vergence on the generation and maintenance of deep moist convection. J. Atmos. Sci., 45, 3606-3624.

Durran, D. R., and J. B. Klemp, 1982: On the effects of moisture on the Brunt-Väisälä frequency. J. Atmos. Sci., 39, 21522158.

Eom, J. K., 1975: Analysis of the internal gravity wave occurrence of 19 April 1970 in the Midwest. Mon. Wea. Rev., 103, 217226.

Fovell, R. G., 2002: Upstream influence of numerically simulated squall-line storms. Quart. J. Roy. Meteor. Soc., 128, 893-912.

- 2005: Convective initiation ahead of the sea-breeze front. Mon. Wea. Rev., 133, 264-278.

—_, and Y. Ogura, 1988: Numerical simulation of a midlatitude squall line in two dimensions. J. Atmos. Sci., 45, 3846-3879.
- and - 1989: Effect of vertical wind shear on numerically simulated multicell storm structure. J. Atmos. Sci., 46, 31443176.

- , and P. S. Dailey, 1995: The temporal behavior of numerically simulated multicell-type storms. Part I: Modes of behavior. J. Atmos. Sci., 52, 2073-2095.

— , and P.-H. Tan, 1998: The temporal behavior of numerically simulated multicell-type storms. Part II: The convective cell life cycle and cell regeneration. Mon. Wea. Rev., 126, 551577.

- D. R. Durran, and J. R. Holton, 1992: Numerical simulations of convectively generated gravity waves in the stratosphere. J. Atmos. Sci., 49, 1427-1442.

Grady, R. L., and J. Verlinde, 1997: Triple-Doppler analysis of a discretely propagating, long-lived, High Plains squall line. $J$. Atmos. Sci., 54, 2729-2748.

Houze, R. A., Jr., 1977: Structure and dynamics of a tropical squall-line system. Mon. Wea. Rev., 105, 1540-1567. , 2004: Mesoscale convective systems. Rev. Geophys., 42, RG4003, doi:10.1029/2004RG000150.

Lin, Y.-L., R. D. Farley, and H. D. Orville, 1983: Bulk parameterization of the snow field in a cloud model. J. Climate Appl. Meteor., 22, 131-157.

Lindzen, R. S., and K.-K. Tung, 1976: Banded convective activity and gravity waves. Mon. Wea. Rev., 104, 1602-1617.

Mapes, B. E., 1993: Gregarious tropical convection. J. Atmos. Sci., 50, 2026-2037.

Nicholls, M. E., R. A. Pielke, and W. R. Cotton, 1991: Thermally forced gravity waves in an atmosphere at rest. J. Atmos. Sci., 48, 1869-1884.

Rotunno, R., J. B. Klemp, and M. L. Weisman, 1988: A theory for strong, long-lived squall lines. J. Atmos. Sci., 45, 463-485.

Scorer, R. S., 1949: Theory of waves in the lee of mountains. Quart. J. Roy. Meteor. Soc., 75, 41-56.

Thorpe, A. J., M. J. Miller, and M. W. Moncrieff, 1982: Twodimensional convection in non-constant shear: A model of midlatitude squall lines. Quart. J. Roy. Meteor. Soc., 108, 739 762.

Tripoli, G. J., and W. R. Cotton, 1989a: Numerical study of an observed orogenic mesoscale convective system. Part I: Simulated genesis and comparison with observations. Mon. Wea. Rev., 117, 273-304.

_ and _ 1989b: Numerical study of an observed orogenic mesoscale convective system. Part II: Analysis of governing dynamics. Mon. Wea. Rev., 117, 305-328.

Weisman, M. L., and J. B. Klemp, 1982: The dependence of numerically simulated convective storms on vertical wind shear and buoyancy. Mon. Wea. Rev., 110, 504-520.

—, and R. Rotunno, 2004: "A theory for strong, long-lived squall lines" revisited. J. Atmos. Sci., 61, 361-382.

Xue, M., K. K. Droegemeier, and V. Wong, 2000: The Advanced Regional Prediction System (ARPS) - A multiscale, nonhydrostatic atmospheric simulation and prediction model. Part I: Model dynamics and verification. Meteor. Atmos. Phys., 75, 161-193.

Yang, M.-J., and R. A. Houze Jr., 1995: Multicell squall-line structure as a manifestation of vertically trapped gravity waves. Mon. Wea. Rev., 123, 641-660.

Zipser, E. J., 1977: Mesoscale and convective-scale downdrafts as distinct components of squall-line structure. Mon. Wea. Rev., 105, 1568-1589. 